\title{
DARING: Pengembangan E-booklet Digital Parenting Cara Mencegah Kecanduan Gadget pada Anak Usia Dini
}

\author{
Mayrina Eka Prasetyo Budi \\ Bimbingan Penyuluhan Islam, Institut Agama Islam Negeri Ponorogo \\ mayrinaekapb@gmail.com
}

\begin{abstract}
This research aims to produce a digital parenting e-booklet which discusses ways to prevent gadget addiction in early childhood. This research is a development research (Research and Development) with the ADDIE model. The stages in the study consisted of analysis, design, development, implementation and evaluation. The data collection methods were interview and questionnaire. The data were analyzed using descriptive statistics. The results showed that the digital parenting $\mathrm{e}^{-}$ booklet product which discusses ways to prevent gadget addiction was successfully created through the development process (Research and Development) with the ADDIE model. Through the validation process, there were scores of $52(86.67 \%) \%)$ from two material experts, $122(90.37 \%)$ scores of two media experts, and 44,125 $(88.25 \%)$ of the eight parents who were used as users. Based on the results of validation of the material, media experts and users in trials can conclude that the parenting digital e-booklet media is appropriate to be used as a medium of information for parents of early childhood.
\end{abstract}

Keywords: Development; Digital parentinge-booklet; Ways to prevent gadget addiction; Early childhood.

Abstrak: Penelitian ini bertujuan menghasilkan e-booklet digital parenting yang membahas cara mencegah kecanduan gadget pada anak usia dini. Penelitian ini merupakan penelitian pengembangan (Research and Development) dengan model ADDIE. Tahapan-tahapan dalam penelitian terdiri dari analisis, desain, development, implementation dan evaluation. Metode pengumpulan data dengan wawancara dan angket. Teknik analisis data menggunakan statistic deskriptif. Hasil penelitian menunjukkan bahwa produk e-booklet digital parenting yang membahas cara mencegah kecanduan gadget pada anak usia dini berhasil dikembangkan melalui proses penelitian pengembangan (Research and Development) dengan model ADDIE. Melalui proses validasi, diperoleh hasil skor 52 (86.67\%) dari dua ahli materi, skor $122(90.37 \%)$ dari dua ahli media, serta skor 44.125 (88.25\%) dari delapan orang tua anak usia dini sebagai pengguna. Berdasarkan hasil validasi dari ahli materi, ahli media dan pengguna dalam uji coba dapat disimpulkan bahwa media e-booklet digital parenting layak digunakan sebagai media informasi bagi orang tua anak usia dini.

Kata kunci: Pengembangan; E-booklet digital parenting; cara mencegah kecanduan gadget; anak usia dini. 


\section{PENDAHULUAN}

Usia dini yaitu rentang usia enam tahun pertama kehidupan seorang anak (UU Sisdiknas Nomor 20 tahun 2003). Usia dini dikenaldengan masa keemasan (Golden Age). Perkembangan kecerdasan mengalami peningkatan yang pesat di usia ini (Sandjaja, 2020). Usia dini menjadi periode yang paling kondusif untuk mengoptimalkan berbagai aspek tumbuhkembanganakyaitufisik, kognitif, bahasa, sosio emosional, dan spiritual. Orang tua berperan penting dalam mengoptimalkan tumbuh kembang anak, sehingga dikatakan orang tua adalah penentu bagi masa depan anak (Suhardi \& Utami, 2019).

Kualitas pengasuhan mempengaruhi perkembangan anak. Berbagai penelitian menunjukkan bahwa pengasuhan menjadifaktor terpenting yang berperan dalam perkembangan anak (Sanders,2008). Di usia Golden Age sangat diperlukan cara pengasuhan yang tepat guna menstimulasi tumbuh kembang buah hati secara optimal. Pola asuh diartikan sebagai cara mendidik anak yang dilakukan orang tua sebagai bentuk tanggung jawab mereka (Ramadhani, Fernanda, Sari, \& Lubis, 2018).

Pola asuh yang kurang tepat sering dijumpai di tengah masyarakat. Hal itu terjadi karena banyak orang tua hanya memiliki sedikit persiapan untuk mengasuh anak. Orang tua mengasuh anak lewat proses trial dan error (Sanders, Dadds, \& Turner, 2003). Salah satu pola asuh yang tidak tepat yaitu membiarkan anak usia dini bermain gadget tanpa batasan dan pendampingan. Orang tua memberikan gadget agar anak duduk tenang, tidak rewel sehingga tidak mengganggu aktifitas mereka. Anak-anak di Indonesia waktunya terbuang lebih dari satu jam dalam sehari dipakai melihat televisi (54.4\%), menyalakan video (30\%), menikmati buku (8.2\%), menyalakan komputer (32.5\%), serta $(67.3 \%)$ bermain dengan permainan elektronik (Hendriyani, Hollande, d'Haenes, \& Beetjes,2014). Pemakaian smartphone mencapai 94\% pada anakusia Taman Kanak-Kanak (TK) 4-6 tahun (Zaini \& Suenarto, 2019). Fenomena anak-anak berusia kurang dari satu tahun telah dikenalkan dengan gadget disampaikan oleh Direktur Pusat Pendidikan untuk Perempuan dan Anak (PUPA) Bengkulu, Susi Handayani (Azhar,2019). Anak usia di bawah dua tahun idealnya bebas dari gadget, sedangkan usia dua hingga lima tahun penggunaannya dibatasi satu jam per hari untuk program berkualitas disertai pendampingan orang tua. Adapun untuk anak berusia enam tahun atau lebih perlu ada batasan durasi yang konsisten (American Academy of Pediatrics, 2001).

Orang tua menjadikan gadget sebagai digital baby sister di tengah kesibukan mereka. Fenomena ini menunjukkan bahwa orang tua belum mengetahui dan memahami dampak negatif gadget. Salah satu dampak negatif gadget yaitu terjadinya gadget addiction atau kecanduan gadget. Pemberian gadget di usia dini memperbesar kemungkinan anak akan mengalami kecanduan. Ketua Komisi Perlindungan Anak Indonesia (KPAI) menyampaikan orang tua yang tidak mengetahui anaknya terindikasi kecanduan gadget di tengah banyak anak kecanduan gawai menjadi tantangan besar (Kompas, 2018). Biasanya orang tua baru menyadari setelah kondisi anak cukup parah. Jumlah pasien anak yang mengalami kecanduan gadget di berbagai rumah sakit makin meningkat. RSJ Cisarua Propinsi Jawa Barat adalah salah satu RS yang sudah merawat ratusan pasien, dan setiap bulan menangani 10-12 pasien anak kecanduan gadget (Yuwono, 2019).

Tugas orang tua adalah menjaga dan melindungi anak-anaknya dengan baik agar tidak mengalami kecanduan gadget (Astri, 2019). Orang tua perlu mengetahui banyak hal mengenai pengasuhan, sayangnya tidak ada sekolah untuk itu (Savitri, 2019). Agar orang tua mengetahui dan memahami tentang pengasuhan yang dapat mencegah anak dari kecanduan gadget diperlukan media pemberi informasi. Saat ini masih belum banyak media 
informasi yang memberikan pengetahuan tentang pengasuhan dalam menggunakan media digital, seperti komputer, telepon genggam (handphone), telepon cerdas (smartphone), dan lain sebagainya.

Latar belakang di atas memunculkan ketertarikan peneliti untuk membuat sebuah media informasi berupa e-booklet digital parenting. Diharapkan e-booklet ini dapat digunakan sebagai media informasi bagi orang tua tentang cara mencegah anak kecanduan gadget pada anak usia dini. E-booklet (Electronic Book) adalah bentuk digital dari sebuah booklet dan termasuk media berbasis elektronik. Media berbasis elektronik memiliki beberapa karakteristik utama yaitu materinya ringkas, menarik dan mudah dipahami dengan dilengkapi banyak gambar, video dan rekaman suara (Fatimah \& Mufti, 2014; Asyhari \& Diani, 2017).

E-booklet lebih ringkas daripada booklet cetak. Pengguna telepon cerdas serta perangkat genggam lainnya dapat membuka e-booklet kapan dan dimana saja. E-booklet lebih awet sebab berbentuk digital, sehingga tidak mudah rusak dibanding booklet cetakan. Ebooklet lebih ramah lingkungan daripada booklet biasa sebab tidak membutuhkan tinta serta kertas. Penelitian ini bertujuan menghasilkan ebooklet digital parenting yang membahas cara mencegah kecanduan gadget pada anak usia dini. Bagaimana membuat e-booklet digital parenting yang membahas cara mencegah kecanduan gadget pada anak usia dini menjadi rumusan masalah dalam penelitian ini. Metode Research and Development (R\&D) dengan model ADDIE adalah metode yang digunakan dalam penelitian ini. Metode analisis menggunakan statistik deskriptif.

\section{METODE}

Penelitian dan pengembangan (Research and Development) menjadi desain dalam penelitian ini (Arkun \& Akkoyunlu, 2008). Penelitian ini menggunakan model ADDIE yang sudah dimodifikasi yang terdiri dari lima tahap yaitu Analysis, Design, Development, Implementation dan Evaluation. Sampel diambil memakai teknik sampling jenuh. Seluruh populasi dipakai sebagai sampel, disebabkan populasinya relatif kecil kurangdari 30 orang (Sugiyono, 2017). Yang dijadikan sampel yaitu para orang tua dari anak usia dini (0-6 tahun) dan tinggal di Grand Saphire Residence Ponorogo. Perumahan ini dihuni oleh keluarga dengan tingkat ekonomi menengah keatas dengan beragam latar belakang pendidikan dan pekerjaan. Sampel penelitian ini berjumlah delapan orang.

Pengumpulan data dilakukan dengan wawancara dan menggunakan instrumen. Wawancara yaitu metode mendapatkan data dimana pewawancara mengajukan pertanyaan kepada nara sumber, bias dilakukan secara langsung yaitu tatap muka atau menggunakan telepon (Nayak \& Priyanka, 2016). Wawancara dipakai untuk mengetahui kebutuhan orang tua terhadap e-booklet digital parenting, serta pendapat mereka terhadap media e-booklet digital parenting yang dikembangkan. Instrumen digunakan guna melihat kelayakan dari media $\mathrm{e}^{-}$ booklet digital parenting berdasarkan penilaian para ahli, serta keefektifanebooklet digital parenting berdasarkan respon pengguna. Ada tiga instrument yang digunakan yaitu instrumen validasi ahli materi, instrumen validasi ahli media dan angket pengguna.

Teknik analisis data melalui statistik deskriptif dengan menggunakan skala likert.Analisis statistik deskriptif yaitu statistik yang dipakai menganalisis data yang terkumpul asli apa adanya, tanpa menyusun kesimpulan umum atau generalisasi (Sugiyono, 2017). Data yang berasal dari angket ahli isi atau materi, ahli media atau desain, dan angket ujicoba respon pengguna dianalisis memakai skala likert dengan rentang skor 1-5, yaitu sangat kurang baik (1), kurang baik (2), cukup baik (3), baik (4), dan sangat baik (5). Tingkat pencapaian masing-masing komponen dengan dihitung dengan memakai rumus: 
Persentase $=\frac{\sum(\text { jawaban bobottiap pilihan })}{n \times \text { bobottertinggi }} \times 10 \%$

E-booklet digital parenting yang membahas cara mencegah kecanduan gadget pada anak usia dini dinyatakan memenuhi kriteria baik atau layak dari segi materi, dan segi media, serta efektif jika presentase nilai yang diperoleh dari analisis data adalah $\geq 61 \%$ (Riduwan, 2012).

Tabel 1. Kriteria Skala Likert

\begin{tabular}{ll}
\hline \multicolumn{1}{c}{ Skor } & \multicolumn{1}{c}{ Kriteria } \\
\hline $0 \%-20 \%$ & Sangat tidak memenuhi \\
$21 \%-40 \%$ & Tidak memenuhi \\
$41 \%-60 \%$ & Kurang memenuhi \\
$61 \%-80 \%$ & Memenuhi \\
$81 \%-100 \%$ & Sangat memenuhi \\
\hline
\end{tabular}

\section{HASIL}

Tahapan yang dilakukan dalam pembuatan E-booklet Digital Parenting adalah sebagaiberikut. Analysis. Tahap analysis bertujuan untuk menganalisis kebutuhan akan e-booklet digital parenting. Dilakukan analisa pengetahuan orang tua yaitu para ibu tentang dampak negatif gadget dan cara mencegah anak kecanduan gadget, serta analisa kebutuhan akan e-booklet digital parenting. Dari wawancara, peneliti mendapati para ibu di perumahan Grand Saphire Ponorogo belum memiliki pengetahuan yang mendalam tentang dampak negatif gadget dan cara mencegah anak kecanduan gadget.

Mereka membiarkan anak bermain gadget sejak kecil bahkan sebelum anak berusia dua tahun. Ada orang tua yang memiliki anak berusia 18 bulan dan sulit dijauhkan dari gadget. Para orang tua juga belum pernah mendapatkan informasi tentang dampak negatif gadget dan cara mencegah kecanduan gadget pada anak. Mereka menyampaikan perlunya media informasi yang praktis semacam $\mathrm{e}^{-}$ booklet yang menjelaskan kepada mereka tentang dampak negatif gadget dan cara mencegah anak kecanduan gadget.

Design. Tahap desain dilakukan untuk membuat desain awal e-booklet digital parenting untuk mencegah anak kecanduan gadget. Ada lima tahapan dalam merancang e-booklet. Pertama merumuskan tujuan pembuatan $\mathrm{e}^{-}$ booklet yaitu memberikan informasi dampak negatif gadget dan cara mencegah kecanduan gadget pada anak usia dini. Kedua menetapkan format ebooklet yaituhalamansampul, kata motivasi, kata pengantar, daftar isi , materi atau isi, referensi, profil penulis. Ketiga perumusan konsep materi yang akan disampaikan. Ada lima materi yang disampaikan di dalam e-booklet ini, yaitu (a) Data kecanduan gadget pada anak yang berasal dari berbagai sumber; (b) Panduan penggunaan gadget menurut American Academy of Pediatrics (American Academy of Pediatrics, 2001); (c) Cri-ciri kecanduan gadget menurut penelitian yang berjudul Screen Dependency Disorder :A New Challenge for Children Neurology yang dimuat pada Journal of The International Child Neurology (Sigman,2017); (d) Dampak negatif gadget menurut penelitian yang berjudul The Impact of using Gadgets on Children yang dimuat di Journal of Depression and Anxiet (Sundus, 2018). Dampak negatif gadget menurut Bill Gates dan Melinda (Wulansari, 2017); (e) Tips agar anak tidak kecanduan gadget sesuai yang disarankan American Academy of Pediatrics (AAP, 2001), dan theAsianparent (Wulansari, 2017), serta dari penelitian Sundus M (Sundus, 2018). Keempat, menentukan konsep pesan yaitu dampak negatif gadget dan cara mencegah kecanduan gadget di usia dini, serta posisi utama orang tua untuk mencegah anak kecanduan gadget. Kelima menentukan konsep kreatif, yaitu gaya visual, tipografi huruf, layout dan warna. Jenis ilustrasi gambar yang dipakai adalah ilustrasi gambar vektor dua dimensi (flat design) yang digambar menggunakan aplikasi CorelDRAW X7 dan mengambil dari situs untuk download free vector yakni freepik.com (beberapa gambar dimodifikasi sesuai dengan kebutuhan).

Tipografi huruf yang digunakan adalah DIN dan Segoe UI karena elegan dan mudah dibaca, serta ada kesan lebih 
modern. Layout dibuat standar dan menyesuaikan kebutuhan yaitu tidak terlalu banyak gambar atau foto, hanya terdapat beberapa ilustrasi, dan dengan margin yang standar. Warna yang digunakan adalah warna cerah dan soft menyesuaikan dengan konsep visual yang ditampilkan. Huruf menggunakan warna biru (ice blue) dan hitam. Background menggunakan warna biru muda. Warna biru dipilih karena materi e-booklet berkaitan dengan teknologi. Background juga disertai dengan gambar yang memperjelas maksud materi yang ingin disampaikan.

Development. Tahap ini bertujuan mengembangkan e-booklet digital parenting untuk mencegah anak kecanduan gadget yang sudah direncanakan sesuai format agar menjadi produk yang bagus. Agar $\mathrm{e}^{-}$ booklet menjadi produk yang bagus mengharuskan untuk mendapatkan perbaikan serta saran melalui para pakar. Ada beberapa pakar yang dilibatkan yaitu ahli materi yang kompeten dalam melakukan validasi terhadap isi atau materi dan ahli media atau desain, yang kompeten dalam melakukan validasi terhadap desain $\mathrm{e}^{-}$ booklet yang dibuat. Di dalam tahap Development dilakukan dua proses validasi menggunakan instrumen yang dibuat oleh peneliti, yaitu validasi isi atau materi dan validasi media atau desain dari e-booklet digital parenting. Proses validasi isi atau materi dilakukan oleh dua orang validator ahli materi yaitu Lia Amalia, M.Si, (validator 1) dan Kayyis Fithria Ajhuri, M.A (validator 2). Keduanya adalah dosen Jurusan Bimbingan Penyuluhan Islam (BPI) IAIN Ponorogo dengan keahlian di bidang psikologi anak dan keluarga.

Tabel 2. Rekapitulasi Hasil Validasi Ahli Materi

\begin{tabular}{ccccl}
\hline No & Validator & Skor & $\begin{array}{c}\% \\
\text { Skor }\end{array}$ & Kesimpulan \\
\hline 1 & $\begin{array}{l}\text { Validator } \\
1\end{array}$ & 46 & $76,7 \%$ & $\begin{array}{l}\text { Sangat } \\
\text { memenuhi }\end{array}$ \\
\hline 2 & $\begin{array}{l}\text { Validator } \\
2\end{array}$ & 58 & $96,7 \%$ & $\begin{array}{l}\text { Sangat } \\
\text { memenuhi }\end{array}$ \\
\hline Skor rata rata & 52 & $86,7 \%$ & $\begin{array}{l}\text { Sangat } \\
\text { memenuhi }\end{array}$ \\
\hline
\end{tabular}

Dari proses validasi isi atau materi ada beberapa saran dan masukan yang disampaikan oleh validator, yaitu Ernest Doku sebagai shocking statement di bagian awal sebaiknya diganti dengan data kecanduan di Indonesia atau pernyataan tokoh atau ahli dari Indonesia, dan perlu diberikan penjelasan arti beberapa istilah yang digunakan dalam e-booklet, serta pada bagian akhir sebaiknya diberi penutup singkat sebagai kesimpulan dan pengingat bagi pembaca. Proses validasi media atau desain juga melibatkan dua orang validator ahli media atau desain yaitu Galih Akbar Prabowo, M.A (validator 1) dosen Desain dan Fotografi dan Asna Istya Marwantika, M.Kom.I. (validator 2) dosen Media Jurnalistik. Keduanya berasal dari jurusan Komunikasi dan Penyiaran Islam (KPI) IAIN Ponorogo. Berikut data hasil penilaian oleh validator ahli media atau desain:

Tabel 3. Rekapitulasi Hasil Validasi Ahli Media

\begin{tabular}{llccl}
\hline No & Validator & Skor & \% Skor & Kesimpulan \\
\hline 1 & $\begin{array}{l}\text { Validator } \\
1\end{array}$ & 122 & $90,4 \%$ & $\begin{array}{l}\text { Sangat } \\
\text { memenuhi }\end{array}$ \\
\hline $\begin{array}{l}\text { Validator } \\
2\end{array}$ & 122 & $90,4 \%$ & $\begin{array}{l}\text { Sangat } \\
\text { memenuhi }\end{array}$ \\
Skor rata rata & 122 & $90,4 \%$ & $\begin{array}{l}\text { Sangat } \\
\text { memenuhi }\end{array}$ \\
\hline
\end{tabular}

Dari proses validasi media atau desain ada dua saran dan masukan yang disampaikan oleh validator yaitu kontras warna judul dan backgroud kurang maksimal, dan perlu menambah sampul belakang yang berisi pesan yang layout yang senada dengan sampul depan. Implementation. Uji coba dilakukan di perumahan Grand Saphire Ponorogo. Peserta ujicoba berjumlah delapan orang tua dari anak usia dini. Kegiatan ujicoba bertujuan untuk mengukur kefektifan penggunaan $\mathrm{e}^{-}$ booklet yang telah dikembangkan jika digunakan di lapangan yang sebenarnya. Uji coba juga bertujuan untuk mendapat masukan dan saran terkait $\mathrm{e}^{-}$ booklet dari pengguna, sehingga bisa dilakukan perbaikan. Selain itu, ujicoba juga dilakukan untuk mengetahui 
berbagai kesulitan pengguna ketika menggunakan e-booklet, dengan demikian peneliti bisa mencari solusi dari permasalahan tersebut.

Ujicobapenggunadilakukan dengan memberikan instrumen berupa angket respon pengguna yang dibuat oleh peneliti. Dari penyebaran angket respon pengguna diperoleh data sebagai berikut:

Tabel 4. Rekapitulasi Penilaian Pengguna

\begin{tabular}{lllllllllllllll}
\hline No & $\begin{array}{c}\text { Nama } \\
\text { Pengguna }\end{array}$ & \multicolumn{1}{c}{ Item Pertanyaan } & \multicolumn{1}{c}{ Jml } & $\%$ \\
\cline { 3 - 13 } & & 1 & 2 & 3 & 4 & 5 & 6 & 7 & 8 & 9 & 10 & & \\
1 & LS & 5 & 4 & 5 & 5 & 4 & 5 & 5 & 5 & 5 & 5 & 48 & $96 \%$ \\
2 & ER & 5 & 3 & 5 & 3 & 5 & 5 & 4 & 3 & 3 & 5 & 41 & $82 \%$ \\
3 & AG & 4 & 4 & 4 & 4 & 4 & 4 & 5 & 4 & 4 & 5 & 42 & $84 \%$ \\
4 & FD & 4 & 4 & 5 & 5 & 5 & 4 & 4 & 4 & 5 & 5 & 45 & $90 \%$ \\
5 & DA & 4 & 5 & 5 & 5 & 4 & 3 & 5 & 5 & 3 & 5 & 44 & $88 \%$ \\
6 & EM & 5 & 4 & 4 & 4 & 5 & 5 & 4 & 5 & 4 & 4 & 44 & $88 \%$ \\
7 & LY & 5 & 4 & 4 & 4 & 5 & 5 & 4 & 4 & 4 & 5 & 44 & $88 \%$ \\
8 & PS & 4 & 5 & 5 & 5 & 5 & 4 & 5 & 4 & 4 & 4 & 45 & $90 \%$ \\
\hline
\end{tabular}

Ada dua saran dan masukan yang disampaikan pengguna pada uji coba, yaitu adanya kesalahan penulisan katadan ilustrasi gambar yang belum ada keterangannya. Guna memperbaiki e-booklet digital parenting dilakukan dua kali revisi produk. Revisi pertama dilakukan mengacu pada saran, masukan dan hasil validasi ahli materi dan ahli media. Adapun perbaikan pada revisi pertama yaitu mengganti pernyataan Ernest Doku dengan pernyataan tokoh dari Indonesia, serta data kecanduan di Indonesia, menambah halaman glosarium untuk memberikan keterangan istilah-istilah khusus yang terdapat pada e-booklet, menambah halaman penutup dan kesimpulan $\mathrm{e}^{-}$ booklet sebagai pengingat bagi pembaca, membuat warna judul dan backgroud lebih kontras serta menambah sampul belakang. Revisi kedua dilakukan mengacu pada saran, masukan dan hasil angket pengguna. Adapun revisi yang dilakukan pada revisi kedua yaitu memperbaiki tulisan pada kata-kata yang masih salah, seperti kata lambing menjadi lambat, dan menambahkan keterangan pada ilustrasi gambar.
Evaluation. Kegiatan evaluasi dilakukan untuk menyempurnakan $\mathrm{e}^{-}$ booklet yang sudah direvisi dan melihat kembali proses pembuatan yang dilakukan sudah sesuai dengan tahapan atau belum. Tujuan utama kegiatan evaluasi adalah melihat secara keseluruhan terhadap e-booklet yang dibuat dan memastikan semua masukan dari validator dan pengguna telah digunakan untuk perbaikan e-booklet, sehingga diperoleh produk akhir $\mathrm{e}^{-}$ booklet yang layak digunakan. Dari hasil evaluasi didapatkan e-booklet ini sudah dibuat sesuai dengan tahapan dan semua masukan validator serta pengguna juga telah digunakan dalam perbaikan. Produk akhir e-booklet ini berjudul Digital Parenting: Mencegah Anak Kecanduan Gadget. E-booklet terdiri dari 20 halaman yang tersusun mulai dari sampul depan, kata motivasi, kata pengantar, daftar isi, materi, penutup dan kesimpulan, referensi, profil penulis, grosarium, sampul belakang.

\section{PEMBAHASAN}

Penelitian ini termasuk jenis penelitian dan pengembangan (Research and Development). Penelitian ini menghasilkan produk e-booklet digital parenting dengan materi dampak negatif gadget dan cara mencegah kecanduan gadget pada anak usia dini. Terdapat beberapa masalah yang melatar belakangi pembuatan produk. Masalah tersebut meliputi: a. kasus kecanduan gadget pada anak usia dini yang semakin banyak; b. kurangnya pengetahuan dan kemampuan orang tua tentang dampak negatif gadget dan cara mencegah kecanduan gadget pada anak usia dini; c. belum banyak media informasi berbasis elektronik yang membahas dampak negatif gadget dan cara mencegah kecanduan gadget pada anak usia dini.

E-booklet digital parenting telah berhasil dibuat dengan metode penelitian dan pengembangan ( Research and Development ). Ini membuktikan bahwa metode tersebut merupakan metode penelitian yang dapat memproduksi produk tertentu dan 
menguji keefektifan produk tersebut (Sugiyono, 2015). Penelitian ini telah mengikuti tahapan -tahapan metode penelitian dan pengembangan dengan model ADDIE (Analysis, Desain, Development, Implementation dan Evaluation) yang sudah dimodifikasi dan terdiri dari lima Langkah ( Arkun \& Akkoyunlu, 2008). Penelitian ini diawali dengan analisis kebutuhan akan produk e-booklet digital parenting. Selanjutnya melakukan desain atau perancangan produk dengan menetapkan tujuan pembuatan, menetapkan format $\mathrm{e}^{-}$ booklet, merumuskan konsep materi dan pesan yang akan disampaikan, menentukan konsep kreatif dengan pemilihan elemen visual yang meliputi gaya visual, tipografi huruf, layout, dan warna.

Selanjutnya, tahap pengembangan produk terdiri dari pembuatan instrumen validasi dan melakukan validasi ahli atau expert appraisal. Produk awal e-booklet digital parenting divalidasi oleh ahli materi dan ahli media. Ahli materi dan ahli media memvalidasi sebanyak satu kali, hal ini disebabkan skor rata-rata hasil validasi materi dan media menunjukkan nilai yang termasuk kategori sangat memenuhi, sehingga sudah memenuhi standar layak untuk diujicobakan. Produk e-booklet digital parenting direvisi berdasarkan saran dan masukan ahli materi dan media. Tahap berikutnya adalah implemetasi dengan melakukan uji coba pengguna. Ujicoba dilaksanakan dengan cara memberikan produk e-booklet digital parenting kepada para orang tua di perumahan Grand Saphire Ponorogo. Peneliti memberikan angket pengguna kepada delapan orang tua anak usia dini. Selain meminta orang tua mengisi angket, peneliti melakukan wawancara terhadap mereka. Berdasarkan hasil dari angket, saran dan masukan pengguna, produk e-booklet digital parenting kembali direvisi. Tahap terakhir yang dilakukan adalah melakukan evaluasi. Ini dilakukan untuk menyempurnakan produk yang sudah direvisi dan melihat kembali proses pengembangan yang dilakukan sudah sesuai dengan tahapan atau belum. Tujuan utama dari kegiatan evaluasi adalah melihat secara keseluruhan terhadap produk yang dikembangkan dan memastikan semua masukan dari validator dan pengguna digunakan untuk perbaikan produk sehingga diperoleh produk akhir $\mathrm{e}^{-}$ booklet digital parenting yang berkualitas.

E-booklet digital parenting ini dinyatakan layak untuk dipakai berdasarkan hasil validasi ahli atau expert appraisal. Thiagarajan, $\mathrm{dkk}$ (1974), "expert appraisal is a technique for obtaining suggestions for the improvement of the material'. Tehnik ini adalah tehnik guna mengetahui validasi dan nilai kelayakan rancangan produk. E-booklet memenuhi kriteria baik dari segi isi atau materi jika presentase nilai yang diperoleh dari analisis data adalah $\geq 61 \%$ (Riduwan, 2012). Tabel 2 menunjukkan nilai validasi dari ahli materi atau isi terhadap e-booklet digital parenting. Dari validasi diperoleh skor rata-rata sebesar 52 dengan presentase $86,67 \%$. Berdasarkan skor tersebut $\mathrm{e}^{-}$ booklet digital parenting termasuk kategori sangat memenuhi, sehingga layak dipakai sebagai media informasi untuk orang tua darianak usia dini. Kelayakan e-booklet ini sebagai media informasi dapat dilihat dari kesesuaian materi yang disampaikan dengan tujuan pembuatan e-booklet, kejelasan materi, kebenaran materi, penulisan materi, kerunutan materi, tata bahasa, dan kedalaman materi. Tabel 3 menunjukkan nilai validasi dari ahli media atau desain terhadap e-booklet digital parenting. Dari validasi diperoleh skor rata-rata sebesar 122 dengan presentase 90,37\%. Marujuk skor tersebut e-booklet digital parenting terkategori sangat memenuhi, sehingga layak untuk digunakan sebagai media informasi bagi orang tua anak usia dini. Kelayakan e-booklet sebagai media informasi dapat dilihat dari ukuran produk, desain sampul, desain isi produk, dan penggunaan bahasa.

Guna mengetahui keefektifan $\mathrm{e}^{-}$ booklet digital parenting dilakukan ujicoba pengguna di perumahan Grand Saphire Ponorogo. Peserta ujicoba 
berjumlah delapan orang tua dari anak usia dini. E-booklet memenuhi kriteria baik jika presentase nilai yang diperoleh dari analisis data adalah $\geq 61 \%$ (Riduwan, 2012). Hasil angket pengguna ditunjukkan pada tabel 3. Dari ujicoba pengguna didapatkan skor rata-rata sebesar 44,125 dengan presentase $88,25 \%$. Berdasarkan skor tersebut $\mathrm{e}^{-}$ booklet digital parenting terkategori sangat memenuhi, sehingga efektif untuk digunakan sebagai media informasi bagi orang tua dari anak usia dini. Keefektifan e-booklet sebagai media informasi dapat dilihat dari lengkap dan bervariasinya materi atau informasi yang disampaikan sesuai dengan perkembangan jaman, penyampaian materi mudah dipahami dan diaplikasikan karena pemilihan kata dan bahasa sesuai dengan kemampuan pengguna apalagi dilengkapi dengan tampilan e-booklet yang menarik, sehingga menumbuhkan rasa ingin tahu pengguna. Hal ini sesuai dengan $\mathrm{e}^{-}$ booklet sebagai media berbasis elektronik yang memiliki beberapa karakteristik utama yaitu materinya ringkas, menarik dan mudah dipahami dengan dilengkapi banyak gambar, video dan rekaman suara (Fatimah \& Mufti, 2014; Asyhari \& Diani, 2017).

Keefektifan e-booklet ini juga tampak dari hasil wawancara yang dilakukan peneliti dalam uji coba pengguna. Salah satu pengguna yaitu LS menyampaikan "Menurut saya ini sangat membantu sekali, karena anak sekarang banyak yang kecanduan dengan gadget dan sulit untuk dihindari. Dengan pencegahan tersebut bagi saya sangat membantu dan bermanfaat, alangkah baiknya para orangtua mencegah daripada membiarkan" (wawancara, 11 Juli 2020). Hal senada juga disampaikan oleh ketujuh pengguna yang lain yaitu ER, AG,FD,DA,EM,LY,PJ (wawancara, 11 Juli 2020). E-booklet ini cukup mampu menumbuhkan kesadaran orang tua untuk lebih memperhatikan anak dalam menggunakan gadget. Hal ini terungkap saat uji coba pengguna. Salah satu orang tua yaitu FD mengakui kesalahannya "Ini saya kuliah daring, repot dengan HP/laptop, anak saya kalau tau minta.
Akhirnya saya berikan. Anak saya yang masih 18 bulan sampun ngertos (sudah tahu) HP. Saya merasa bersalah. Ko' anak kurang 2 tahun saya bolehin $H P$ " (wawancara,11 Juli 2020). Ketujuh orang tua yang lain (AG,FD,DA,EM,LY,PJ) juga menyampaikan hal yang hampir sama yaitu merasa bersalah memberikan gadget pada anak tanpa memberi batasan (wawancara,11 Juli 2020).

Fokus penelitian ini adalah menghasilkan produk e-booklet digital parenting yang layak dipakai sebagai salah satu media pemberi informasi tentang dampak negatif gadget dan cara mencegah kecanduan gadget pada anak usia dini. Melalui tahapan-tahapan dalam penelitian dan pengembangan telah dihasilkan e-booklet dengan judul Digital Parenting: Mencegah Anak Kecanduan Gadget yang terdiri dari 20 halaman dan telah teruji kelayakan dan keefektifannya. Kekurangan penelitian ini yaitu tidak sampai menggali sejauhmana bertambahnya pengetahuan orang tua setelah mendapatkan $\mathrm{e}^{-}$ booklet ini.

\section{SIMPULAN}

Media e-booklet digital parenting yang membahas cara mencegah kecanduan gadget pada anak usia dini telah dihasilkan dengan metode Research and Development (R \& D) melalui model ADDIE (Analysis, Design, Development, Implementation, dan Evaluation). Berdasarkan hasil validasi ahli materi dan media, serta hasil ujicoba pengguna menunjukkan bahwa media e-booklet digital parenting ini layak dan efektif digunakan sebagai sarana pemberi informasi bagi orang tua yang memiliki anak usia dini. 
American Academy of Pediatrics Committee on Public Education. 2001. Children, Adolencents, and Television. Pediatr. 107 (2):423-6.

Arkun, Selay \& Buket Akkoyunlu.2008. A Study on the Development Process of a Multimedia Learning Environment According to the ADDIE Model and Students Opinions of the Multimedia Learning Environment. IEMJournal, 2008:1-19.

Astri, R.D. 2019. Parenting 4.o Mendidik Anak Di Era Digital.Klaten: Caesar Media Pustaka.

Asyhari, A., \& Diani, R.2017. PembelajaranFisikaBerbasis Web Enhanced Course: Mengembangkan Web-Logs PembelajaranFisika Dasar I. JurnalInovasiTekonologi Pendidikan 4(1):13-25.

Azhar, R. (2019, 18 Desember). 70 Persen Anak Kecanduan Gadget. Diunduh pada 19 Februari 2020, darihttps://bengkuluekspress.com/ 70-persen-anak-kecanduan-gadget.

Fatimah, S., Mufti, Y.2014. Pengembangan Media Pembelajaran IPA-Fisika Smartphone Berbasis Android SebagaiPenguatKarakter Sains Siswa.J. Kaunia 10 (1):59-64.

Hendriyani,Hollander,E.,d'Haenes,L.,\&B eentjes,J. 2014. Views on children's media use in Indonesia:Parents, children, and teachers. International Communication Gazette 76 (45):322-339.

Kompas. (2018,23

Juli). KecanduanGawaiAncam Anakanak.Diunduh pada10 Juli 2020, darihttp://kominfo.go.id/content/de tail/13547/kecanduan-gawaiancam-anakanak/O/sorotan_medial.

Nayak, J.K, \& Priyanka, S. 2016. Fundamentals of Methodology: Problems and Prospects. New Delhi: SSDN Publishers and Distributor.
Ramadhani, M.R, Fernanda,R., Sari, R., \&Lubis, H. 2018. Peran Pola Asuh Orang

TuadalamMembentukKarakterPe duliLingkungan.

JurnalPsikostudia, Vol.7, No.2,6170.

Riduwan. 2012. Skala Pengukuran Variabel -Variabel Penelitian. Bandung: Alfabeta.

Sanders, M.R.2008. Triple P-Positive Parenting Program as a Public Health Approach to Strengthening Parenting. Journal of Family Psychology, 506-517.

Sanders, M.R., Dadds, C.M., \& Turner, K.M. 2003. Theoretical, Scientific and Clinical Foundations of the Triple P-Positive Parenting Program: A Population Approach to the Promotion of Parenting Competence. Queensland: The University of Queensland.

Sandjaja

M.

2020 PengaruhPelatihanKeterampilanP engasuhanTerhadapKepekaan dan KeterlibatanOrangtuadengan Anak Prasekolah. JurnalPsikostudia, Vol.9, No.2, 119-126.

Savitri, A. 2019. BijakMendidik Anak di Era Milenial.Yogyakarta:Briliant.

Sigman, A. 2017. Screen Dependency Disorder; A New Challenge for Child Neurology. Journal of the International of the International Child Neurology Association, Mey, 1-15.

Sugiyono.2015. Metode Penelitian dan Pengembangan (Research and Development/ R\&D). Bandung: Alfabeta.

Sugiyono. 2017. Metode Penelitian Kuantitatif, Kualitatif dan R\&D. Alfabeta. Bandung

Sundus, M. 2018. The Impact of using Gadgets on Children.Journal Depress Anxiety, Vol. 7, :1-3.

Suhardi, T \&Utami, E. 2019. Ayah \&Bunda, MengatasiKecanduan Gadget pada Anak. Semarang: Syalmahat Publishing.

Suryani, N., Achmad, S \&Aditin, P. 2018. Media PembelajaranInovatif 
dan Pengembangannya. Bandung :Remaja Rosdakarya.

Yuwono. (2019, 16 Oktober). RSJ Jabar Kebanjiran Pasien Anak yang Ketergantungan Gawai dan Aplikasi. Diunduh pada 19 Februari 2020, dari https://jabar.inews.id/berita/rsjjabar-kebanjiran-pasien-anakyang-ketergantungan-gawai-danaplikasi.

Wulansari, N.M.D. 2017. Didiklah Anak Sesuai Zamannya. Jakarta Selatan: Transmedia Pustaka.

Zaini, M \& Soenarto.2019. Persepsi Orangtua terhadap Hadirnya Era Teknologi Digital di Kalangan Anak Usia Dini. Jurnal Obsesi: Jurnal Pendidikan Anak Usia Dini Vol 3, No 1, 254-264. 